\title{
Nitidine Chloride Is a Mechanism-Based Inactivator of CYP2D6
}

\author{
Xu Mao, Zixia Hu, Qian Wang, Na Zhang, Shenzhi Zhou, Ying Peng, and Jiang Zheng
}

Wuya College of Innovation, Shenyang Pharmaceutical University, Shenyang, Liaoning, P. R. China ${ }^{1}$ (X.M., Z.H., Q.W., N.Z., S.Z., Y.P., J.Z.); State Key Laboratory of Functions and Applications of Medicinal Plants, Key Laboratory of Pharmaceutics of Guizhou Province and Guizhou Medical University, Guiyang, Guizhou, P. R. China ${ }^{1}$ (J.Z.)

Received December 5, 2017; accepted May 11, 2018

\section{ABSTRACT}

Nitidine chloride (NC) is a benzophenanthridine alkaloid isolated from the roots of Zanthoxylum nitidum (Roxb.) DC, a widely used traditional herbal medicine. Several reports have revealed NC's multiple pharmacologic properties. The inhibitory effects of NC on human cytochrome P450 enzymes were investigated in the present study. We found that NC caused time- and concentration-dependent inhibition of CYP2D6, and more than $50 \%$ of CYP2D6 activity was suppressed after a 15-minute incubation with NC at $100 \mu \mathrm{M}$ in the primary incubation mixtures, with $K_{1}$ of $4.36 \mu \mathrm{M}, k_{\text {inact }}$ of 0.052 minute $^{-1}$, and a partition ratio of approximately 290 . Moreover, the loss of CYP2D6 activity required the presence of NADPH. Superoxide dismutase/ catalase and glutathione showed minor protection against the
NC-induced enzyme inhibition. Quinidine as a competitive inhibitor of CYP2D6 slowed down the inactivation by NC. Trapping experiments using $\mathrm{N}$-acetylcysteine demonstrated that quinone and/or carbene intermediate(s) were/was generated in human liver microsomal incubations with NC. In addition, potassium ferricyanide prevented the enzyme from the inactivation mediated by NC, which provided evidence that inhibition of CYP2D6 resulted from heme destruction by the formation of a carbene-iron complex. CYP1A2 was found to be the major enzyme involved in the generation of NC quinone metabolites. In conclusion, NC is a mechanism-based inactivator of CYP2D6. The generation of a carbene intermediate might be mainly responsible for the enzyme inactivation.

\section{Introduction}

Nitidine chloride (NC) belongs to the benzophenanthridine alkaloids and was initially isolated in 1959 (Arthur et al., 1959) from the roots of Zanthoxylum nitidum (Roxb.) DC (Liangmianzhen in Chinese), a classic traditional Chinese medicinal (TCM) plant distributed mainly in northeastern Asia (Liao et al., 2013; Li et al., 2017). The roots of the plant are widely used to treat rheumatism, toothache, neuralgia, and swelling of the throat (Liu et al., 2017). A natural ingredient of toothpaste and soap, $\mathrm{NC}$ has great potential value as a component of consumer products. NC was reported to have significant antimalarial (Gakunju et al., 1995; Bouquet et al., 2012), anti-inflammatory (Hu et al., 2006; Wang et al., 2012), and immunosuppressive activities (Tan et al., 1991). Recently, NC was also shown to have anticancer potential in various human cancer cell lines, including human hepatocellular carcinoma cells (Ou et al., 2015), lung adenocarcinoma cells (Iwasaki et al., 2010a,b), breast cancer cells (Pan et al., 2011), gastric cancer cells (Chen et al., 2012), and renal cancer cells (Fang et al., 2014), which has aroused increased attention.

NC consists of one methylenedioxyphenyl (MDP) and two methoxy functional groups in the structure. Many MDP compounds have been shown to inhibit cytochrome $\mathrm{P} 450$ enzymes (P450s), including reversible and irreversible inhibition (Murray, 2000). Sesamin is the major constituent of sesame oil with powerful inhibitory effect on CYPs 1A2,

This work was supported in part by the National Natural Science Foundation of China [Grants 81373471, 81430086, 81773813]. The authors declare that there are no conflicts of interest.

https://doi.org/10.1124/dmd.117.079780.
2C9, 2C19, 2D6, and 3A4 (Jan et al., 2012). Several plant alkaloids (bulbocapnine, canadine, and protopine) with an MDP moiety similar to that of NC have been identified as potent mechanism-based inactivators (MBIs) of CYP2C19 (Salminen et al., 2011). Myristicin, widely occurring in plants of Umbelliferae family, is an MBI of CYP1A2 (Yang et al., 2015). The most abundant MDP, lignin podophyllotoxin extracted from podophyllin, exerted time-dependent inhibition toward CYP3A4 and concentration-dependent inhibition of CYP3A4 and CYP2C9 (Song et al., 2011). Additionally, it has been reported that MDP groups could be metabolized to generate a catechol by $O$-dealkylation reaction, followed by oxidation to form an electrophilic ortho-quinone (Hutzler et al., 2006, 2008). And carbene, as a free-radical intermediate, is easily produced in this metabolic pathway and can form a metabolic-intermediate complex (MIC) with heme-iron via coordination, leading to quasi-irreversible inhibition of P450s (Taxak et al., 2013). For example, the selective serotonin reuptake inhibitor paroxetine, with an MDP structure, potently inhibits the activity of CYP2D6 by forming an MIC with a carbene-iron complex (Bertelsen et al., 2003). Thus, we speculated that NC as a member of MDP compounds might produce similar inhibitory impact on P450 enzymes.

As important phase I enzymes, P450 enzymes are responsible for a variety of biotransformations of endogenous substrates and xenobiotics, such as drugs, environmental pollutants, and carcinogens (Liu et al., 2017). However, drug-drug interactions (DDIs) are often caused by inhibition of P450s occurring with the metabolism of commonly used drugs (Danton et al., 2013), which frequently changes their toxicity or efficacy (Haefeli and Carls, 2014). To avoid DDIs induced by enzyme inhibition, prediction and identification of compounds with the potential to serve as MBIs of P450s has become an important issue in drug

ABBREVIATIONS: DDQ, 2,3-dichloro-5,6-dicyano-1,4-benzoquinone; GSH, glutathione; IS, internal standard; LC-MS/MS, liquid chromatography coupled to tandem mass spectrometry; MBI(s), mechanism-based inactivator(s); MDP, methylenedioxyphenyl; MRM, multiple-reaction monitoring; NC, nitidine chloride; P450s, cytochrome P450 enzymes; ROS, reactive oxygen species; SOD, superoxide dismutase. 
development. The objectives of this study were: 1) investigation of interactions of $\mathrm{NC}$ with human $\mathrm{P} 450$ enzymes, 2) characterization of reactive metabolites of $\mathrm{NC}$, and 3 ) identification of cytochrome $\mathrm{P} 450$ enzymes participating in metabolic activation of NC.

\section{Materials and Methods}

Chemicals and Materials. Nitidine chloride with purity $>98 \%$ was obtained from Chengdu Push Bio-Technology Co., Ltd. (Chengdu, China). Recombinant human P450 enzymes and human liver microsomes were acquired from BD Gentest (Woburn, MA). Superoxide dismutase (SOD) were purchased from Shanghai Jianglai Biological Technology Co., Ltd. (Shanghai, China). Propranolol, quinidine, dextromethorphan, phenacetin, tolbutamide, 4-nitrophenol, omeprazole, testosterone, coumarin, bupropion $\cdot \mathrm{HCl}, \alpha$-naphthoflavone, methoxsalen, ticlopidine, sulfaphenazole, disulfiram, ketoconazole, NADPH, $\mathrm{N}$-acetylcysteine (NAC), and glutathione (GSH) were acquired from MilliporeSigma (St. Louis, MO). All organic solvents were acquired from Fisher Scientific (Springfield, NJ). Distilled water was obtained from Wahaha Co., Ltd. (Hangzhou, China). All reagents and solvents were analytical or high-performance liquid chromatography grade.

Screening of Time-Dependent P450 Inhibition by NC. To screen the inactivation effect of $\mathrm{NC}$, time-course $\mathrm{P} 450$ enzyme activities were monitored in human liver microsomal incubations after exposure to a single concentration of NC. The primary incubations consisted of microsomes $(0.6 \mathrm{mg} / \mathrm{ml}), \mathrm{MgCl}_{2}$ (3.2 mM), and NC (0 or $100 \mu \mathrm{M})$ in $100 \mu \mathrm{l}$ of $100 \mathrm{mM}$ potassium phosphate buffer ( $\mathrm{pH}$ 7.4). The primary mixtures were preincubated at $37^{\circ} \mathrm{C}$ for 3 minutes. The reactions were initiated by addition of NADPH $(1.0 \mathrm{mM})$. After incubation of the primary mixtures with $\mathrm{NC}$ for the time indicated (0-15 minutes), a $20-\mu 1$ aliquot was removed and added to secondary reaction mixtures $(120 \mu \mathrm{l})$ containing the individual probe substrate, $\mathrm{MgCl}_{2}(2.0 \mathrm{mM})$, and NADPH $(0.5 \mathrm{mM})$, followed by 30 -minute incubations. The resulting reactions were quenched by addition of $120 \mu \mathrm{l}$ ice-cold acetonitrile containing propranolol $(50 \mathrm{ng} / \mathrm{ml})$ as the internal standard (IS). The mixtures were then vortexed for 30 seconds at room temperature and centrifuged at $16,000 \mathrm{rpm}$ for 10 minutes. The supernatants were analyzed by liquid chromatography coupled to tandem mass spectrometry (LC-MS/MS) as described below. The probe substrates and their concentration applied are summarized in Table 1.

Determination of Time-, Concentration-, and NADPH-Dependent Inhibition of CYP2D6 by NC. Human liver microsomes $(0.6 \mathrm{mg} / \mathrm{ml})$ were mixed with $\mathrm{NC}$ at concentrations of $0,1,5,10,50$, or $100 \mu \mathrm{M}$ in $100 \mu \mathrm{l}$ of potassium phosphate buffer ( $\mathrm{pH}$ 7.4) containing $\mathrm{MgCl}_{2}(3.2 \mathrm{mM})$. The reactions were initiated by addition of NADPH (1.0 mM). At time intervals of 0-, 5-, 10-, and 15-minute, aliquots $(20 \mu \mathrm{l})$ were transferred to the secondary incubations containing dextromethorphan $(5.0 \mu \mathrm{M})$ and NADPH $(0.5 \mathrm{mM})$ in potassium phosphate buffer $(\mathrm{pH} 7.4)$ with a total reaction volume of $120 \mu$ l. After a 30-minute incubation, the reaction was stopped by addition of an equal volume of ice-cold acetonitrile containing propranolol (IS) and centrifuged at 16,000 rpm for 10 minutes. The supernatants were analyzed by LC-MS/MS as subsequently described. In a separate study, a similar microsomal incubation with NC $(100 \mu \mathrm{M})$ was performed, but without NADPH, to determine the NADPH dependency of the enzyme inactivation.

Determination of Effect of Quinidine on NC-Mediated Inactivation of CYP2D6. The effect of quinidine, a competitive inhibitor of CYP2D6, was estimated by incubation of $\mathrm{NC}(50 \mu \mathrm{M})$ with human liver microsomes $(0.6 \mathrm{mg} / \mathrm{ml})$ in the presence of quinidine at $0,0.002,0.02,0.2$, and $2.0 \mu \mathrm{M}$ concentrations. The same procedure was executed for reaction initiation, reaction termination, and sample preparation as described above.

Determination of Effects of SOD/Catalase and GSH on NC-Mediated Inactivation of CYP2D6. Nucleophile GSH $(2.0 \mathrm{mM})$ or an equal volume of buffer (control) was included in the primary incubations (final volume: $100 \mu \mathrm{l}$ ) composed of NC (50 $\mu \mathrm{M})$, human liver microsomes $(0.6 \mathrm{mg} / \mathrm{ml})$, and NADPH $(1.0 \mathrm{mM})$. Aliquots $(20 \mu \mathrm{l})$ were taken to the secondary incubation mixtures to determine the remaining enzyme activities at 15 minutes. In a separate experiment, GSH was replaced by SOD and catalase ( $800 \mathrm{IU} / \mathrm{ml}$ for each); other reaction conditions were in accordance with previously described GSH incubations.

Determination of Partition Ratio. Human recombinant CYP2D6 (62.5 nM) was mixed with NC (final concentration: $0,2.5,5,6.25,7.5,10,15,25,50,75$, and $100 \mu \mathrm{M})$ in the primary reactions. The reactions were initiated by mixing with NADPH $(1.0 \mathrm{mM})$, followed by incubation at $37^{\circ} \mathrm{C}$ for 15 minutes to allow the inactivation to go to completion. Aliquots $(20 \mu \mathrm{l})$ were transferred to the secondary reaction mixtures for the measurement of residual catalytic activities as follows.

Determination of Reversibility of NC-Induced CYP2D6 Inhibition by Potassium Ferricyanide. Oxidation with potassium ferricyanide $\left(\mathrm{K}_{3} \mathrm{Fe}(\mathrm{CN})_{6}\right)$ was executed to investigate the reversibility of NC-induced CYP2D6 inhibition, according to a previously reported method (Watanabe et al., 2007) consisting of three sequential incubation reactions. The primary incubations included $0.6 \mathrm{mg} / \mathrm{ml}$ human liver microsomes with or without $100 \mu \mathrm{M} \mathrm{NC}$. Incubation reactions were initiated by addition of NADPH $(1.0 \mathrm{mM})$, and the resulting incubations were carried out for 0,5 , and 15 minutes at $37^{\circ} \mathrm{C}$. Each primary incubation solution $(20 \mu \mathrm{l})$ was then mixed with $20 \mu \mathrm{l}$ of the secondary mixtures in $0.1 \mathrm{M}$ potassium phosphate buffer ( $\mathrm{pH}$ 7.4) containing $\mathrm{K}_{3} \mathrm{Fe}(\mathrm{CN})_{6}$ at $0,0.1,0.2$, and $0.4 \mathrm{mM}$ concentrations. After a 10-minute incubation, the mixtures were diluted 3 -fold with the tertiary incubation solutions that consisted of dextromethorphan $(5.0 \mu \mathrm{M})$ and NADPH $(0.5 \mathrm{mM})$, and sequentially incubated for 10 minutes. The reactions were terminated by addition of equal volume of ice-cold acetonitrile containing propranolol (IS) and centrifuged at 16,000 rpm for 10 minutes. The supernatants $(5 \mu \mathrm{l})$ were analyzed by LC-MS/MS.

TABLE 1

Conditions for P450 activity assays

\begin{tabular}{|c|c|c|c|c|c|}
\hline $\begin{array}{c}\text { P450 } \\
\text { Enzyme }\end{array}$ & Substrate & Concentration $(\mu \mathrm{M})$ & Metabolites & $\begin{array}{l}\text { MRM Scan Mode } \\
\text { (Ion Pair) }\end{array}$ & $\begin{array}{l}\text { HPLC Gradient Elution Condition } \\
\text { (A: Acetonitrile with } 0.1 \% \text { Formic Acid } \\
\text { B: Water with } 0.1 \% \text { Formic Acid) }\end{array}$ \\
\hline $1 \mathrm{~A} 2$ & Phenacetin & 5 & Acetaminophen & {$[\mathrm{M}+\mathrm{H}]^{+} 152.1 \rightarrow 110.0$} & $0-2.0 \mathrm{~min}, 10 \% \mathrm{~A}$ \\
\hline 2B6 & Bupropion & 100 & Hydroxybupropion & {$[\mathrm{M}+\mathrm{H}]^{+} 256.0 \rightarrow 238.0$} & $2.0-2.5 \mathrm{~min}, 10 \%-30 \% \mathrm{~A}$ \\
\hline $3 \mathrm{~A} 4$ & Testosterone & 200 & $6 \beta$-Hydroxytestosterone & {$[\mathrm{M}+\mathrm{H}]^{+} 305.3 \rightarrow 269.4$} & $\begin{array}{c}2.5-14.0 \mathrm{~min}, 30 \%-70 \% \mathrm{~A} \\
14.0-14.1 \mathrm{~min}, 70 \%-90 \% \mathrm{~A} \\
14.1-15.0 \mathrm{~min}, 90 \%-10 \% \mathrm{~A} \\
15.0-17.0 \mathrm{~min}, 10 \% \mathrm{~A}\end{array}$ \\
\hline $2 \mathrm{~A} 6$ & Coumarin & 200 & 7-Hydroxycoumarin & {$[\mathrm{M}-\mathrm{H}]^{-} 161.0 \rightarrow 105.1$} & $0-2.0 \mathrm{~min}, 10 \% \mathrm{~A}$ \\
\hline $2 \mathrm{C} 9$ & Tolbutamide & 200 & 4-Hydroxytolbutamide & {$[\mathrm{M}+\mathrm{H}]^{+} 287.2 \rightarrow 171.2$} & $2.0-5.0 \mathrm{~min}, 10 \%-70 \% \mathrm{~A}$ \\
\hline $2 \mathrm{E} 1$ & 4-Nitrophenol & 30 & 4-Nitrocatechol & {$[\mathrm{M}-\mathrm{H}]^{-} 153.9 \rightarrow 122.8$} & $\begin{array}{c}5.0-10.0 \mathrm{~min}, 70 \%-95 \% \mathrm{~A} \\
10.0-12.0 \mathrm{~min}, 95 \% \mathrm{~A} \\
12.0-13.0 \mathrm{~min}, 95 \%-10 \% \mathrm{~A} \\
13.0-15.0 \mathrm{~min}, 10 \% \mathrm{~A}\end{array}$ \\
\hline $2 \mathrm{C} 19$ & Omeprazole & 20 & 5'-Hydroxyomeprazole & {$[\mathrm{M}+\mathrm{H}]^{+} 362.0 \rightarrow 214.0$} & $0-2.0 \mathrm{~min}, 10 \% \mathrm{~A}$ \\
\hline 2D6 & Dextromethorphan & 5 & Dextrorphan & {$[\mathrm{M}+\mathrm{H}]^{+} 258.2 \rightarrow 157.1$} & $\begin{array}{c}2.0-2.5 \mathrm{~min}, 10 \%-35 \% \mathrm{~A} \\
2.5-8.0 \mathrm{~min}, 35 \%-90 \% \mathrm{~A} \\
8.0-8.1 \mathrm{~min}, 90 \%-10 \% \mathrm{~A} \\
8.1-10.0 \mathrm{~min}, 10 \% \mathrm{~A}\end{array}$ \\
\hline IS & Propranolol & $50 \mathrm{ng} / \mathrm{ml}$ & & {$[\mathrm{M}+\mathrm{H}]^{+} 260.3 \rightarrow 116.3$} & \\
\hline
\end{tabular}


Determination of the Reversibility of NC-Induced CYP2D6 Inhibition through Dialysis. The primary incubations containing $100 \mu \mathrm{M} \mathrm{NC}$ and $0.6 \mathrm{mg} / \mathrm{ml}$ human liver microsomes were performed in the presence of NADPH $(1.0 \mathrm{mM})$ at $37^{\circ} \mathrm{C}$. The control group lacked NC. At 0 and 15 minutes, aliquots of the control and inactivated samples were transferred into Slide-A-Lyzer minidialysis units (molecular mass cut off: 3500 Da; Pierce/Thermo Fisher Scientific) against $100 \mathrm{mM}$ potassium phosphate buffer $\left(\mathrm{pH} \mathrm{7.4,3} \times 2\right.$ hours) at $4^{\circ} \mathrm{C}$. Parallel for the duration of the dialysis experiment. All samples were brought to room analysis was done with nondialyzed samples that had been stored at $4^{\circ} \mathrm{C}$

temperature and added to the secondary incubation solutions for the determination of enzymatic activity as described below.

P450 Enzyme Assays. P450 enzyme activities were assessed by measuring the formation of the corresponding products analyzed by an LC-MS/MS system consisting of $\mathrm{AB}$ Sciex 5500 triple quadrupole mass spectrometer (Applied Biosystems, Foster City, CA) equipped with Agilent 1260 Series Rapid Resolution HPLC (Agilent Technologies, Santa Clara, CA). Chromatographic separations were performed on a Promosil $\mathrm{C}_{18}$ column $(100 \times 4.6 \mathrm{~mm}, 5 \mu \mathrm{m}$; Agela Technologies, Inc., Tianjin, China). The mobile phase was carried out with
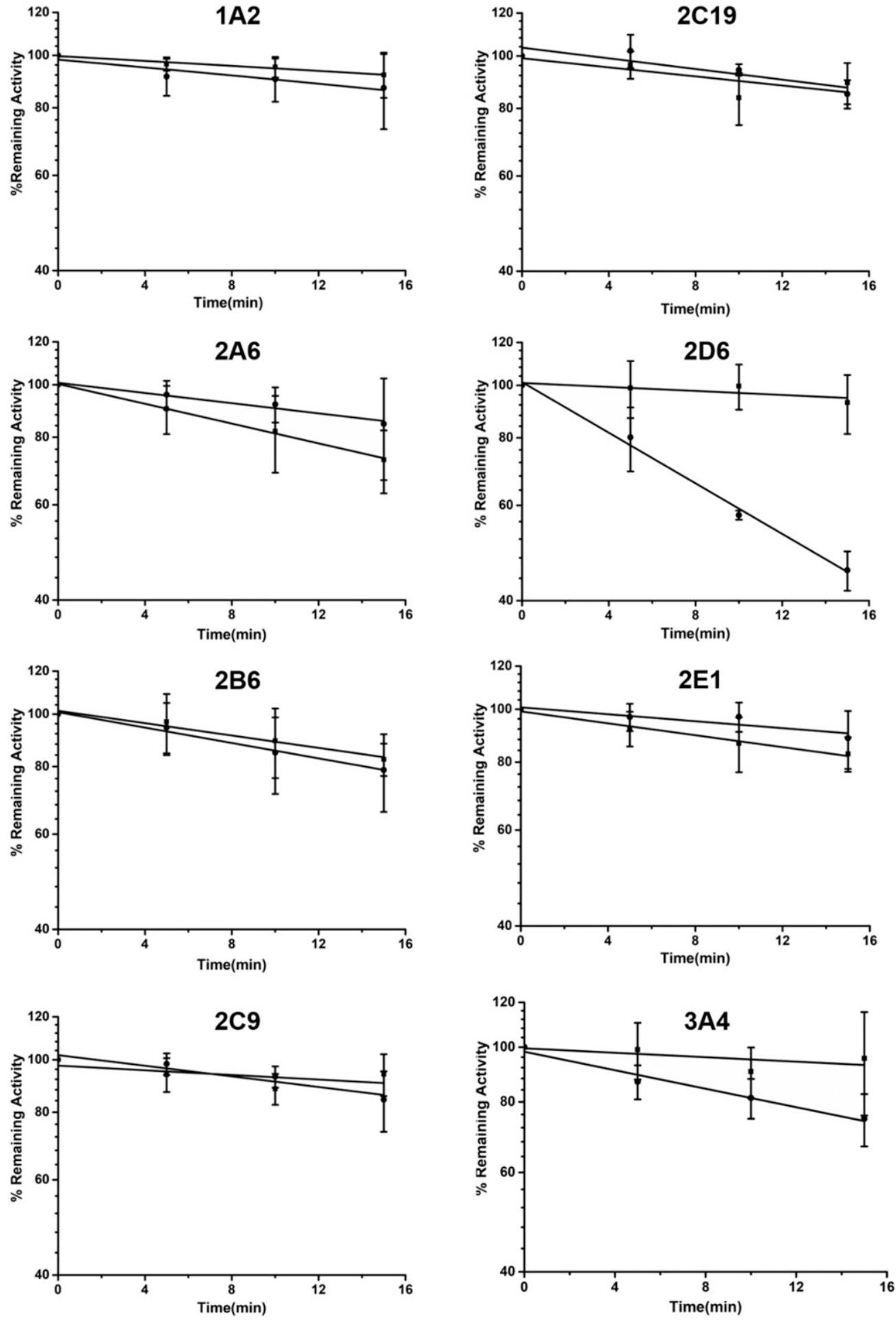

Fig. 1. Screening of time-dependent inhibition of $\mathrm{NC}$ on P450s. Human liver microsomes $(0.6 \mathrm{mg} / \mathrm{ml})$ were incubated with $\mathrm{NC}$ at concentrations of 0 ( the presence of $\mathrm{NADPH}$ at $37^{\circ} \mathrm{C}$ for $0,5,10$, and 15 minutes. The residual enzymatic activities at 0 minutes were normalized to $100 \%$. 
acetonitrile containing $1 \%$ formic acid (A) and water containing $1 \%$ formic acid (B). The flow rate was $0.8 \mathrm{ml} / \mathrm{min}$ and the column temperature was $25^{\circ} \mathrm{C}$. The gradient elution conditions for analyzing the probe substrates are listed in Table 1. The injection volume was $5 \mu$ l. Quantification was performed by multiplereaction monitoring (MRM) scan, and ion pairs of products and propranolol (IS) are shown in Table 1. Among them, products of CYP2A6 and CYP2E1 were analyzed in negative mode, and the others were assessed in positive mode.

Reactive Intermediate Trapping by NAC. NC $(100 \mu \mathrm{M})$ was incubated with human liver microsomes $(1.0 \mathrm{mg}$ protein $/ \mathrm{ml})$ dissolved in phosphate buffer ( $\mathrm{pH}$ 7.4), followed by addition of NAC $(10 \mathrm{mM})$ as a trapping agent. The samples were incubated with or without $1.0 \mathrm{mM} \mathrm{NADPH}$ at $37^{\circ} \mathrm{C}$ for 30 minutes, and the reactions were stopped by mixing with an equal volume ice-cold acetonitrile, followed by vortexing and centrifuging. The resulting supernatants $(5 \mu \mathrm{l})$ were injected into another LC-MS/MS system for analysis. The separation of NAC adducts was achieved on a Promosil $\mathrm{C}_{18}$ column $(100 \times 4.6 \mathrm{~mm}, 5 \mu \mathrm{m}$; Agela Technologies, Inc.), and identification of metabolites was conducted on an SCIEX 4000 hybrid triple quadrupole-linear ion trap (QTRAP) mass spectrometer. The mobile phase system included A (acetonitrile with $0.1 \%$ formic acid) and B (water with $0.1 \%$ formic acid). The flow rate was set at $0.8 \mathrm{ml} / \mathrm{min}$, and analyses were conducted within 15 minutes under the following gradient: 0-2.0 minutes, $10 \% \mathrm{~A} ; 2.0-12.0$ minutes, $10 \%-90 \% \mathrm{~A} ; 12.0-13.0$ minutes, $90 \%-10 \% \mathrm{~A}$; and $13.0-15.0$ minutes, $10 \% \mathrm{~A}$. MS/MS analyses were performed using an MRM-EPI (enhanced product ion) scan in positive-ion mode $(\mathrm{m} / \mathrm{z} 497.1 \rightarrow 368.1$ for NC-NAC adducts).

Chemical Synthesis of NAC-Adducts. NC $(1.0 \mathrm{mg}, 2.6 \mu \mathrm{mol})$ was dissolved in $48 \% \mathrm{HBr}$ aqueous solution $(2.5 \mathrm{ml}, 22.2 \mathrm{mmol})$. The reaction mixture was heated for 12 hours at $80^{\circ} \mathrm{C}$, followed by evaporation of the solvent under vacuum. The resulting solid was dissolved in $\mathrm{CH}_{2} \mathrm{Cl}_{2}(2.0 \mathrm{ml})$ and mixed with $1.0 \mathrm{mg}$ 2,3-dichloro-5,6-dicyano-1,4-benzoquinone (DDQ). The mixture was stirred at $4^{\circ} \mathrm{C}$ for 1 hour. After evaporation of the solvent, the crude products were dissolved in $2.0 \mathrm{ml} \mathrm{H}_{2} \mathrm{O}$ and mixed with NAC $(1.0 \mathrm{mg})$. The mixtures were stirred at the room temperature for 10 hours and then centrifuged at $16,000 \mathrm{rpm}$ for 10 minutes. The supernatants $(5 \mu \mathrm{l})$ were subjected to LC-MS/MS analysis.
Metabolizing-Enzyme Inhibition Studies. Conditions were equivalent to the microsomal incubations except for addition of P450 selective inhibitors $\alpha$-naphthoflavone ( $5 \mu \mathrm{M}$ for 1A2), methoxsalen (10 $\mu \mathrm{M}$ for 2A6), ticlopidine ( $5 \mu \mathrm{M}$ for $2 \mathrm{~B} 6$ and $2 \mathrm{C} 19)$, sulfaphenazole (10 $\mu \mathrm{M}$ for $2 \mathrm{C} 9)$, quinidine ( $5 \mu \mathrm{M}$ for 2D6), disulfiram (50 $\mu \mathrm{M}$ for $2 \mathrm{E} 1$ ), and ketoconazole ( $\mu \mathrm{M}$ for $3 \mathrm{~A}$ ) to the mixtures (Rodrigues, 1999; Wójcikowski et al., 2004; Ma et al., 2018). Control groups lacked the inhibitors in the incubation mixtures. The reactions were terminated by addition of an equal volume of ice-cold acetonitrile containing propranolol (IS) after a 30-minute incubation at $37^{\circ} \mathrm{C}$. The samples were processed as above and subjected to LC-MS/MS for analysis as described above. Incubations were conducted in triplicate, and $\mathrm{P} 450$ activities were expressed as the percentage of the control activities.

Recombinant Human P450 Incubations. NC was individually incubated with human recombinant P450s (100 nM), including CYPs1A2, 2A6, 2B6, 2C9, $2 \mathrm{C} 19,2 \mathrm{D} 6,2 \mathrm{E} 1$, and $3 \mathrm{~A} 4$. Other conditions were identical with the microsomal incubation experiments. A total normalized rate method was applied. The rates of metabolites formed in individual incubations with recombinant P450 enzymes were multiplied by the mean specific content of the corresponding P450 enzymes in human liver microsomes to obtain normalized reaction rates of each enzyme (Rodrigues, 1999).

\section{Results}

Overview of NC-Induced Time-Dependent Inhibition of P450 Enzymes. A quick screening study was performed to determine the inactivation effect of $\mathrm{NC}$ on eight P450 enzymes. Human liver microsomes were incubated with $\mathrm{NC}(100 \mu \mathrm{M})$, and the remaining activities of the eight P450 enzymes were monitored after a 0 - to 15-minute incubation. As shown in Fig. 1, a significant loss of CYP2D6 was observed in 15 minutes, but the activities of the other P450 enzymes examined remained almost unchanged.
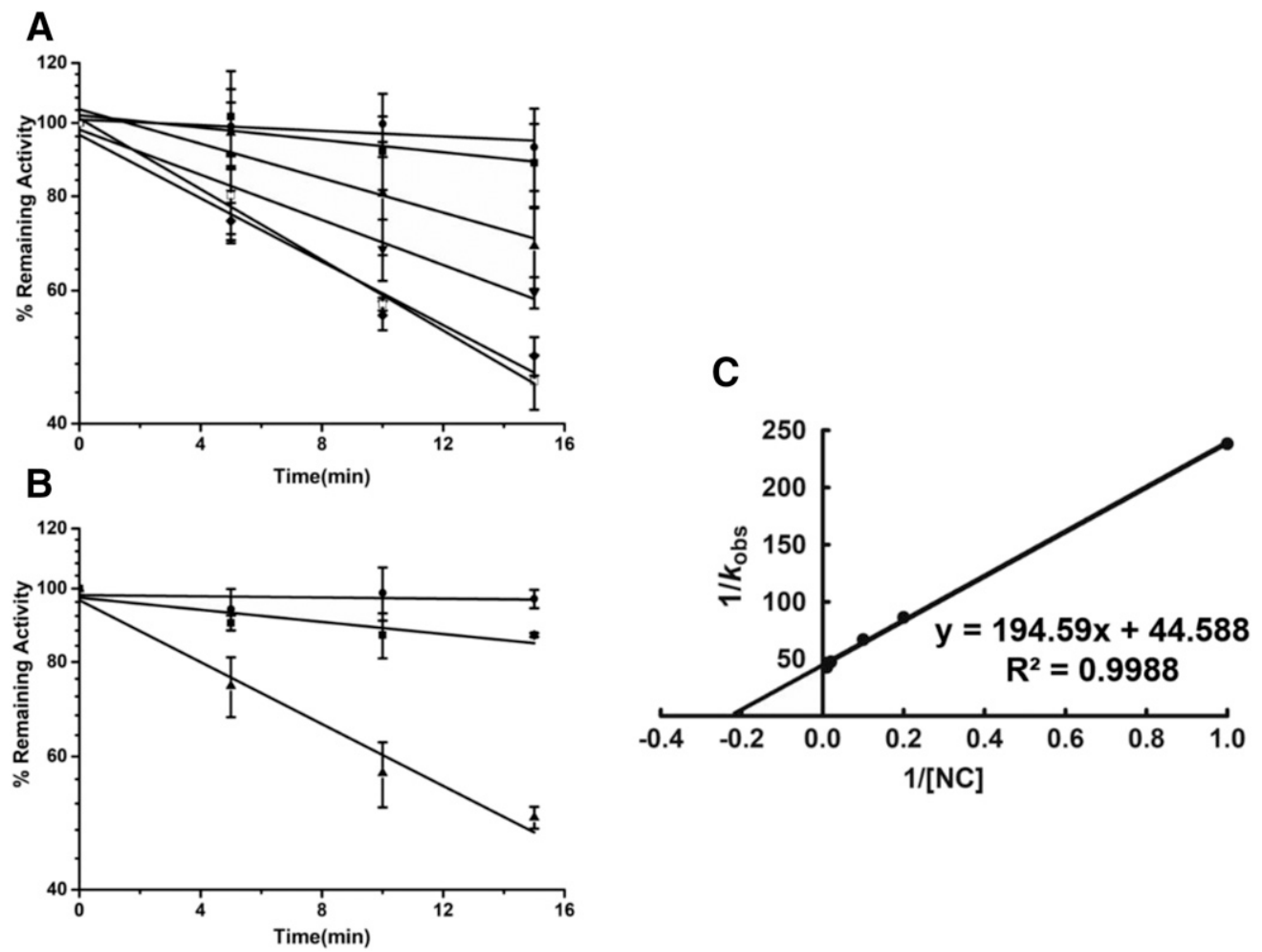

Fig. 2. Time- and concentration-dependent inhibition of CYP2D6 by NC (A). Human liver microsomes $(0.6 \mathrm{mg} / \mathrm{ml})$ were incubated with NC at concentrations of 0 ( $)$, $1(\boldsymbol{\square}), 5(\boldsymbol{\Delta}), 10(\boldsymbol{\nabla}), 50(\bullet)$, or $100(\square) \mu \mathrm{M}$ in the presence of NADPH at $37^{\circ} \mathrm{C}$ for $0,5,10$, and 15 minutes. (B) NADPH-dependent inactivation of CYP2D6 by NC. Human liver microsomes $(0.6 \mathrm{mg} / \mathrm{ml})$ was incubated with vehicle $(\bullet)$ and $\mathrm{NC}(100 \mu \mathrm{M})$ in the absence $(\boldsymbol{\square})$ or presence $(\mathbf{\Lambda})$ of NADPH. (C) Wilson plot. $k_{\mathrm{obs}}$ values were calculated from the slope of the regression lines shown in (A). Data represent the mean \pm S.D. $(n=3)$. 
Time-, Concentration-, and NADPH-Dependent Inhibition of CYP2D6 by NC. Human liver microsomes were incubated with $\mathrm{NC}$ at various concentrations in the absence or presence of NADPH. At various time points, the remaining CYP2D6 activity of the incubation was monitored by measuring the production of dextrorphan. As shown in Fig. 2, A and B, the inhibition of CYP2D6 by NC was found to be time-, concentration-, and NADPH-dependent. The residual enzymatic activities at 0 minutes were normalized to $100 \%$ at each concentration. About $55 \%$ of CYP2D6 activity was lost after incubation with $100 \mu \mathrm{M} \mathrm{NC}$ for 15 minutes at $37^{\circ} \mathrm{C}$. Kinetic values were calculated by a doublereciprocal plot (Wilson plot) of the observed rates of inactivation $\left(k_{\mathrm{obs}}\right)$ and NC concentrations, using GraphPad Prism 5 software (GraphPad Co. Ltd., La Jolla, CA) (Fig. 2C). $K_{\mathrm{I}}$ and $k_{\text {inact }}$ were found to be $4.36 \mu \mathrm{M}$ and 0.052 minutes $^{-1}$, respectively.

Protection Effect of Competitive Inhibitor on NC-Mediated CYP2D6 Inactivation. Quinidine, a competitive inhibitor of CYP2D6, was employed to study the NC-induced inactivation of CYP2D6. The metabolic activity of CYP2D6 was restored progressively with application of increasing concentrations of quinidine (Fig. 3). The remaining enzyme activity in the absence of quinidine was $53.3 \% \pm 3.7 \%$ at 15 minutes, whereas the corresponding activity in the presence of quinidine $(2 \mu \mathrm{M})$ was $80.7 \% \pm 4.3 \%$.

Protection Effect of Ferricyanide on NC-Induced CYP2D6 Inactivation. Selective oxidation of carbene-iron complex is a common approach to probe the involvement of the complex in P450 enzyme inactivation. $\mathrm{NC}$ was incubated with human liver microsomes for 15 minutes in the absence or presence of $\mathrm{K}_{3} \mathrm{Fe}(\mathrm{CN})_{6}$. The enzyme inactivation was alleviated with increased concentrations of $\mathrm{K}_{3} \mathrm{Fe}(\mathrm{CN})_{6}$ (Fig. 4). CYP2D6 activity was regained by $27.6 \%$ in incubations with $0.4 \mathrm{mM} \mathrm{K}_{3} \mathrm{Fe}(\mathrm{CN})_{6}$, compared with absence of $\mathrm{K}_{3} \mathrm{Fe}(\mathrm{CN})_{6}$.

Reversibility of Inactivation. Reversibility of CYP2D6 inhibition was examined by determining whether dialysis can recover the enzyme activity after exposure to NC. A loss of CYP2D6 activity $(9.0 \% \pm 0.8 \%$ of control) was observed after human liver microsomes were incubated with $\mathrm{NC}(100 \mu \mathrm{M})$ at $37^{\circ} \mathrm{C}$ for 15 minutes. The inhibitory effect of NC on CYP2D6 was greatly reduced by dialysis, and the activity was restored to $81.1 \% \pm 17.3 \%$ compared with that of control.

Effects of GSH and SOD/Catalase on Enzyme Inactivation. NC was mixed with GSH to evaluate the protective effect of a nucleophile against the enzymatic inactivation induced by NC. After a 15-minute

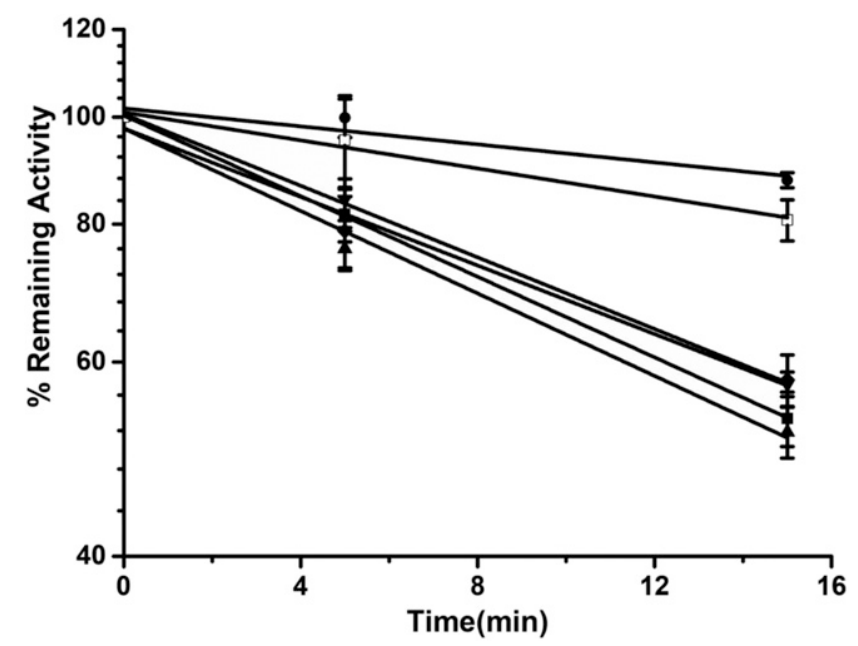

Fig. 3. Effect of competitive inhibitor on inactivation of CYP2D6 by NC. Human liver microsomes $(0.6 \mathrm{mg} / \mathrm{ml})$ were incubated with vehicle $(\bullet)$ and $\mathrm{NC}(50 \mu \mathrm{M})$ in the absence $(\boldsymbol{\square})$ or presence of quinidine at concentrations of $0.002(\boldsymbol{\Delta}), 0.02(\boldsymbol{\nabla})$, $0.2(\diamond)$, or $2(\square) \mu \mathrm{M}$. Data represent the mean \pm S.D. $(n=3)$.

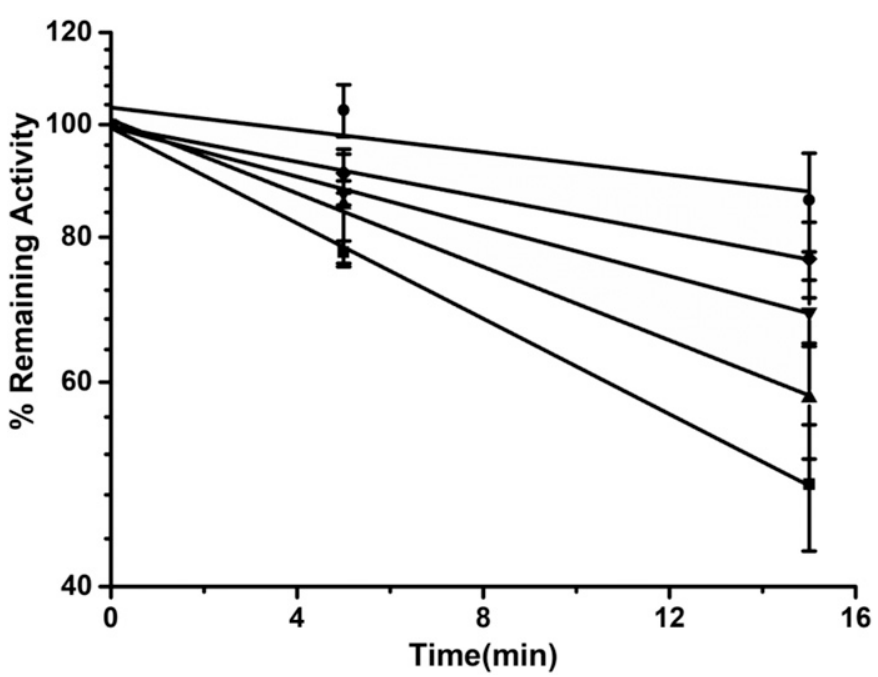

Fig. 4. Protective effect of $\mathrm{K}_{3} \mathrm{Fe}(\mathrm{CN})_{6}$ against inactivation of CYP2D6 by NC. Human liver microsomes $(0.6 \mathrm{mg} / \mathrm{ml})$ were incubated with vehicle $(-)$ and $\mathrm{NC}$ $(100 \mu \mathrm{M})$ in the absence $(\boldsymbol{\square})$ or presence of $\mathrm{K}_{3} \mathrm{Fe}(\mathrm{CN})_{6}$ at concentrations of $0.1(\boldsymbol{\Delta})$, $0.2(\boldsymbol{\nabla})$, or $0.4(\diamond)$ mM. Data represent the mean \pm S.D. $(n=3)$.

incubation, the residual CYP2D6 activities were found to be $62.5 \% \pm 3.2 \%$ with GSH and $55.8 \% \pm 1.8 \%$ without GSH (Table 2). In addition, a mixture of SOD and catalase, scavengers of reactive oxygen species (ROS), was included in the primary reaction solution to investigate their protection of CYP2D6 against inhibition by NC, which showed that $60.9 \% \pm 1.9 \%$ activity of enzyme remained after a 15-minute incubation. The results indicate that GSH and SOD/catalase produced minor protective impacts on inactivated CYP2D6.

Partition Ratio for Inactivation of CYP2D6 by NC. The percentage of activity remaining was plotted as a function of the NC/CYP2D6 molar ratio. As shown in Fig. 5, the partition ratio ( $P$ value) was estimated from the intercept of the linear regression line obtained from the lower ratios of NC to P450 with the straight line derived from higher ratios of NC to $\mathrm{P} 450$. Because the turnover number $(P+1)$ was about 291, $P$ was around 290.

Formation of NAC Adducts Derived from Metabolic Activation of NC. Human liver microsomes were incubated with NC fortified with NAC as the trapping agent. The resulting mixture was analyzed by LC-MS/MS. M1, M2, and M3 eluted out at 7.40, 7.55, and 7.93 minutes, respectively (Fig. 6B). The three metabolites shared the same $[\mathrm{M}+\mathrm{H}]^{+}$at $m / z$ 497.1, and the observed molecular ions of the three suggest an NAC incorporation in the structure of NC. However, no such peaks were found in the control group without NADPH (Fig. 6A), indicating that the generation of the metabolites was NADPH-dependent. The MS/MS spectra of the three NC-NAC adducts were obtained by MRM-EPI scanning (ion transition $\mathrm{m} / \mathrm{z} 497.1 / 368.1$ ), displaying the major fragments at $m / z, 368,335$, and 307 (Fig. 6, D-F). The product ion

TABLE 2

Effects of GSH and SOD/catalase on the inactivation of CYP2D6

\begin{tabular}{lc}
\hline & Remaining Activity (\%) \\
\hline Control (NC) & $55.8 \pm 1.8$ \\
$\mathrm{NC}+\mathrm{GSH}$ & $62.5 \pm 3.2^{*}$ \\
$\mathrm{NC}+\mathrm{SOD} /$ Catalase & $60.9 \pm 1.9^{*}$ \\
\hline
\end{tabular}

Data represent the mean \pm S.D. $(\mathrm{n}=3)$ compared with control group. $* P<0.05$. 


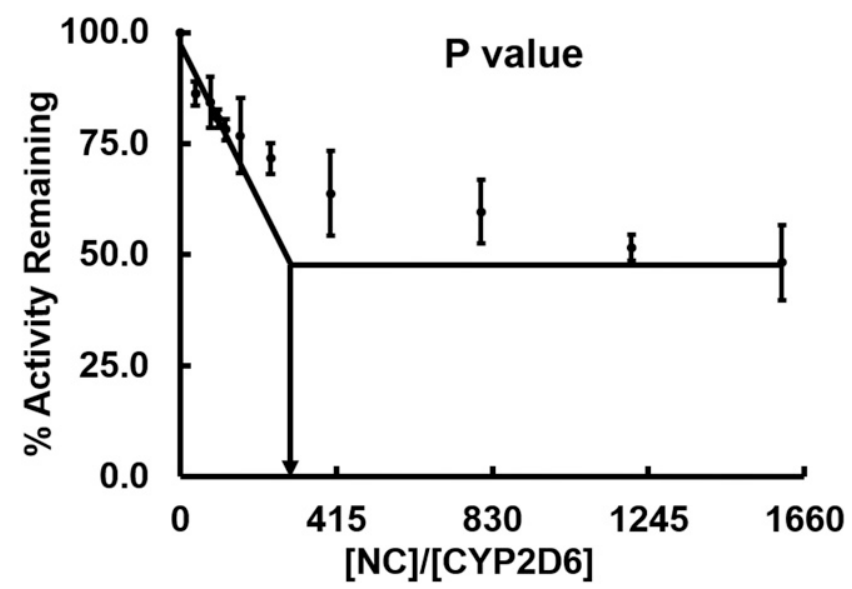

Fig. 5. Partition ratio of CYP2D6 inactivation by NC. CYP2D6 $(62.5 \mathrm{nM})$ was incubated with $\mathrm{NC}$ at various concentrations. The extrapolated $P+1$ values were determined from the point of intersection to the abscissa. Data represent the mean \pm S.D. $(n=3)$.

at $m / z, 368$ showed the characteristic neutral loss of $129 \mathrm{Da}$ associated with the cleavage of the NAC moiety, and the ion at $\mathrm{m} / \mathrm{z} 335$ was derived from the loss of intact NAC.
Chemical synthesis was performed to characterize the metabolites detected in microsomal incubations. NC was chemically demethylenated by $\mathrm{HBr}$, followed by oxidation with DDQ. The resulting mixture was further reacted with NAC. As expected, the three products showed the same chromatographic behaviors (Fig. 6C) and identical mass spectra (data not shown) as that of the NAC adducts (M1-M3) generated in the microsomal reactions. Unfortunately, we were unable to obtain enough of the individual products for nuclear magnetic resonance characterization, owing to the complexity and poor reaction yield.

P450 Enzymes Responsible for NC Bioactivation. Human recombinant $\mathrm{P} 450$ enzyme experiments were performed to determine which P450 enzymes were responsible for the metabolic activation of NC. Eight P450s were individually incubated with $\mathrm{NC}$ in the presence of NADPH and NAC, followed by monitoring of the formation of M1-M3. For each $\mathrm{P} 450$, the reaction rate was multiplied by the mean specific content of the corresponding P450 (e.g., picomoles of P450 per milligram) in native human liver microsomes (Rodrigues, 1999). We found that multiple P450 enzymes catalyzed M1-M3 formation. CYP1A2 showed the most potent catalytic activity, followed by CYP3A4 (Fig. 7A).

In addition, eight $\mathrm{P} 450$ selective inhibitors, including $\alpha$-naphthoflavone (CYP1A2 inhibitor), methoxsalen (CYP2A6 inhibitor), ticlopidine

\section{A}
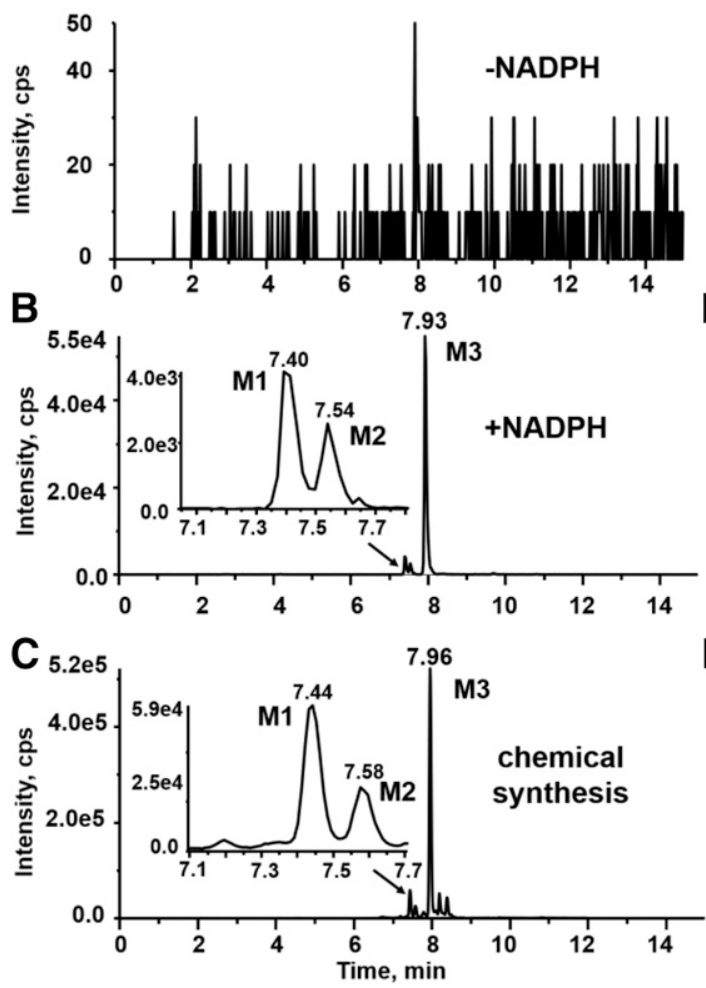
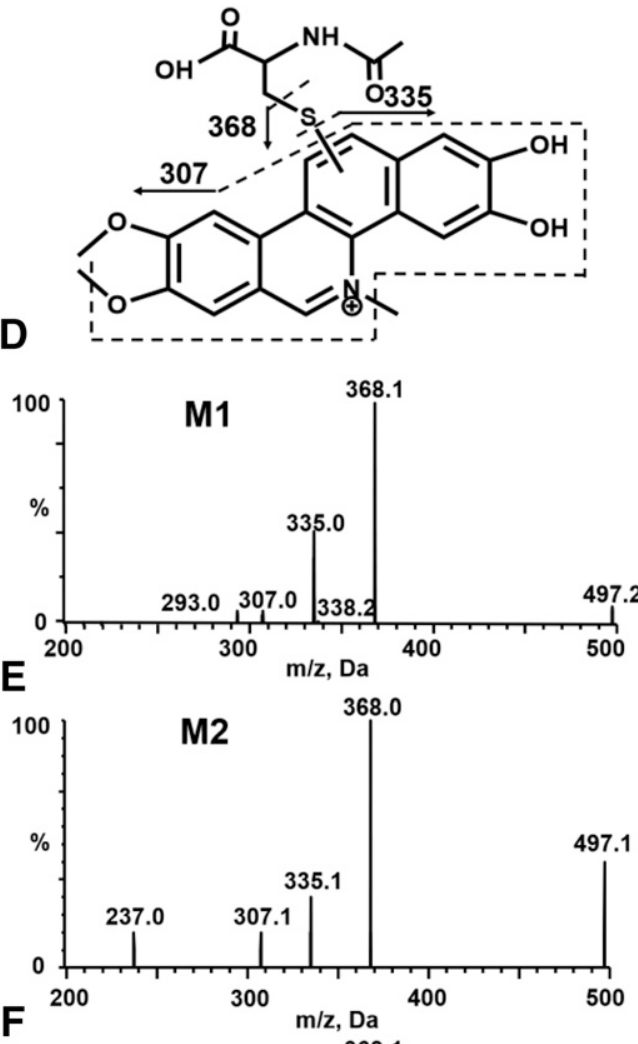
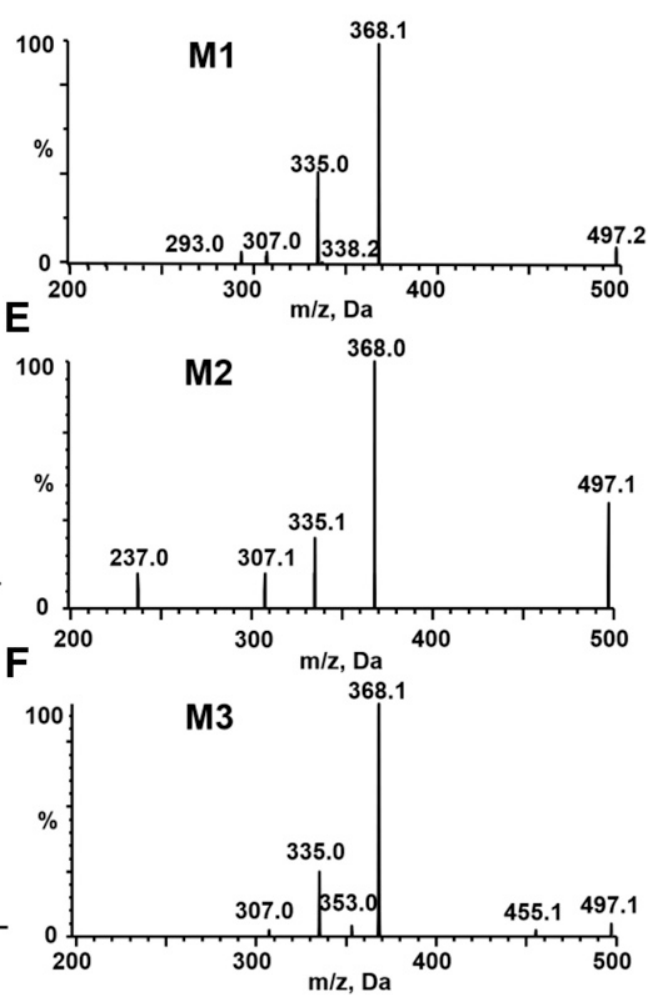

Fig. 6. Mass spectrometric characterization of metabolites M1, M2, and M3. Extracted ion ( $\mathrm{m} / \mathrm{z}$ 497.1/368.1 for M1-M3) chromatograms obtained from LC-MS/MS analysis of incubations containing human liver microsomes, NC, and NAC in the absence (A) or presence of NADPH (B). (C) Extracted ion chromatograms obtained from LC-MS/MS analysis of synthetic M1, M2, and M3. MS/MS spectra of M1 (D), M2 (E), and M3 (F) generated in microsomal incubations. 
A

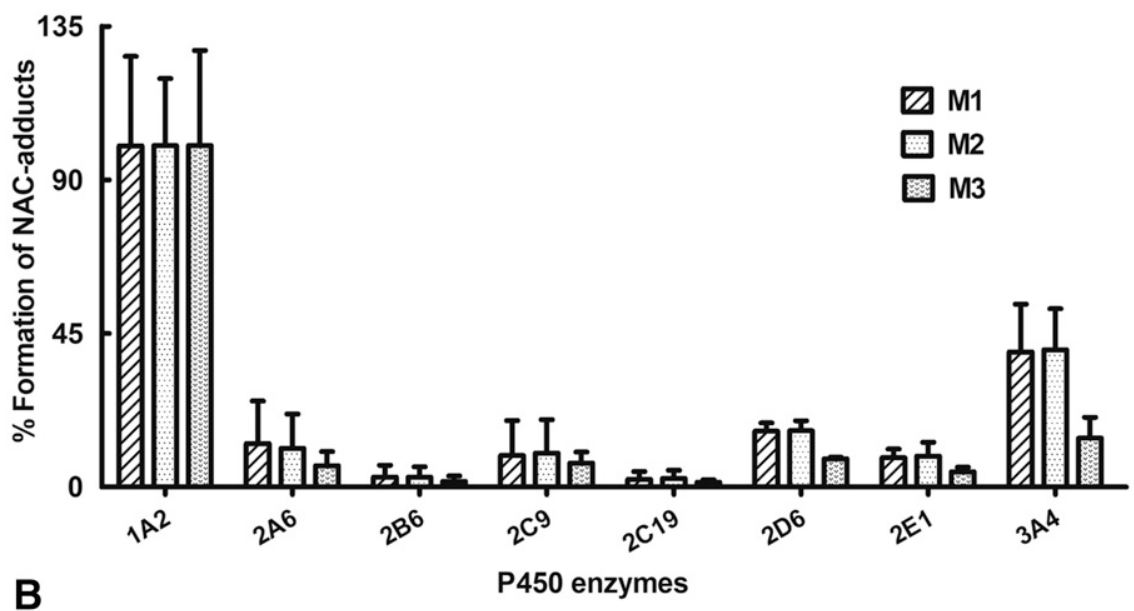

Fig. 7. Metabolic formation of three NC-NAC adducts (M1, M2, and M3) in vitro. (A) Rates of M1-M3 formation in incubations of $\mathrm{NC}$ with individual recombinant $\mathrm{P} 450$ enzymes after normalization on the basis of the relative content of the corresponding P450 enzyme in human liver microsomes. (B) Effects of selective P450 inhibitors on the

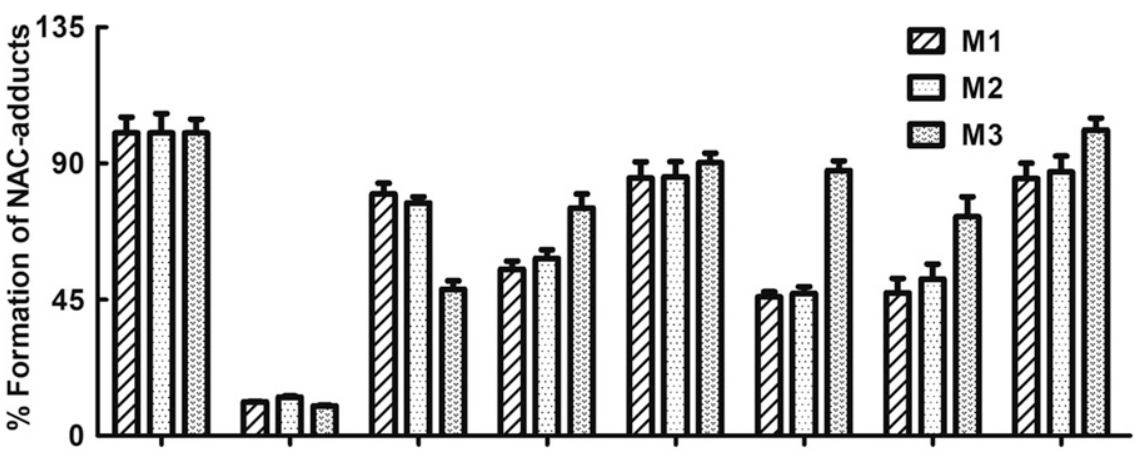
formation of M1-M3. NC was incubated with human liver microsomes, NAC, and NADPH in the absence (control) or presence of individual P450 enzyme inhibitors. Data represent the mean \pm S.D. $(n=3)$.

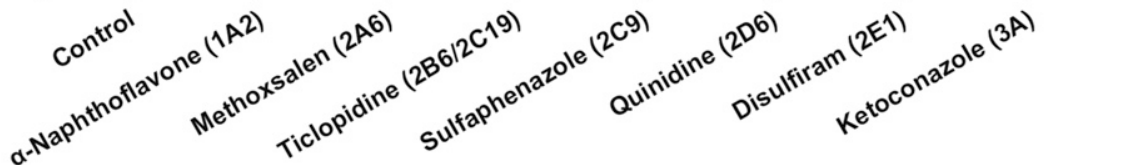

P450 inhibitors

(CYPs 2B6 and 2C19 inhibitor), sulfaphenazole (CYP2C9 inhibitor), quinidine (CYP2D6 inhibitor), disulfiram (CYP2E1 inhibitor), and ketoconazole (CYP3A inhibitor) were individually included in the $\mathrm{NC}$-microsome system in the presence of NAC as the trapping agent. As shown in Fig. 7B, $\alpha$-naphthoflavone elicited a significant inhibitory effect on the formation of M1-M3 $(88.8 \%, 87.3 \%$, and $90.2 \%)$. No or minor inhibition was observed in the microsomal incubations with the other inhibitors. Both the recombinant enzyme and inhibitor experiments demonstrated that CYP1A2 is the main P450 enzyme that mediated the bioactivation of $\mathrm{NC}$ to generate the reactive metabolites. However, no time-dependent inhibition of CYP1A2 was observed in early screening study (Fig. 1).

\section{Discussion}

A quick screening process was conducted to evaluate time-dependent inhibitory effects of $\mathrm{NC}$ on eight P450 enzymes in human liver microsomal incubations. A significant loss of CYP2D6 activity was found after 15-minute microsomal incubation. Further kinetic study clearly demonstrated that NC produced a time- and concentrationdependent inhibition of CYP2D6 with $K_{\mathrm{I}}$ and $k_{\text {inact }}$ of $4.36 \mu \mathrm{M}$ and 0.052 minute $^{-1}$, respectively (Fig. 2). The inactivation induced by NC was not observed in the primary incubation mixture without NADPH, suggesting that the enzyme inactivation was mediated by biotransformation of P450s.
The competitive inhibitor study showed that quinidine attenuated NC-induced inactivation of CYP2D6 in a concentration-dependent manner (Fig. 3), which suggests that the competitive reversible inhibitor entered the active site and protected the enzyme from inactivation (Moruno-Dávila et al., 2001). The observation also indicates that the bioactivation of NC occurred at the active site of CYP2D6.

Generation of reactive intermediates is generally the key factor for mechanism-based enzyme inactivation. The methylenedioxyphenyl group of NC was probably involved in the enzyme inactivation. We speculated that the methylenedioxyphenyl moiety of NC was biotransformed to the corresponding ortho-quinone or carbene metabolites, which might have resulted in the CYP2D6 inactivation. To characterize the reactive metabolites, NAC was employed to trap the quinone metabolite possibly generated in the incubation mixture. As expected, we successfully detected three NAC adducts (M1-M3) by LC-MS/MS (Fig. 6B and Scheme 1). The data indicate the production of NC-derived ortho-quinone or carbene intermediates and the participation of cytochrome P450 enzymes in the metabolic activation of NC. Additionally, chemical synthesis was executed to verify the metabolite identification. The resulting products showed the same chromatographic and mass spectrometric identities as M1-M3 detected in the microsomal incubations.

Covalent modification of $\mathrm{P} 450$ apoprotein, alkylation of heme moiety, or destruction of heme-iron group via formation of metabolicintermediate complex are considered the triggers of the enzyme 
inactivation (Erve et al., 2013). The assay for potassium ferricyanide protection against CYP2D6 inactivation was performed to determine the type of enzyme inhibition. We found that the presence of $\mathrm{K}_{3} \mathrm{Fe}(\mathrm{CN})_{6}$ slowed down the CYP2D6 inactivation induced by NC (Fig. 4). This finding indicates that CYP2D6 inactivation caused by NC belongs to the quasi-irreversible inhibition, owing to the formation of a carbene-iron complex. The binding between the P450 heme and metabolite is a noncovalent tight form, and enzyme activity can be regained by dialysis (Bertelsen et al., 2003; Fowler and Zhang, 2008). The reversibility of CYP2D6 inactivation mediated by $\mathrm{NC}$ was examined by dialysis of the enzyme exposed to $\mathrm{NC}$, and significant recovery of enzyme activity was observed after dialysis.

GSH is a well known nucleophilic biomolecule and was employed to trap the reactive intermediate possibly released from the active site of the enzyme. Only minor protection against enzyme inactivation by NC was observed in GSH-supplemented incubations (Table 2), indicating that the inactivation took place in the active site of the targeting enzyme. ROS scavenger (SOD and catalase) revealed little protection of CYP2D6 from NC-mediated enzyme inactivation (Table 2), suggesting that ROS did not make significant contributions to the enzyme inactivation.

Partition ratio ( $P$ value) is usually used to evaluate the enzyme inactivating efficiency. Reported $P$ values for mechanism-based inactivations of $\mathrm{P} 450 \mathrm{~s}$ ranged from 3 (highly efficient inactivators) to $>1000$ (inefficient) (Kent et al., 2001). The measured $P$ value of NC was about 290 (Fig. 5), which may be classified as a moderately efficient inactivator.

Additionally, metabolic studies with human recombinant enzymes showed that multiple P450 enzymes contributed to the metabolic activation of NC. CYP1A2 primarily catalyzed bioactivation of NC, followed by CYP3A4 (Fig. 7A). Furthermore, coincubation with $\alpha$-naphthoflavone (CYP1A2 inhibitor) in human liver microsomes significantly attenuated the formation of the three NAC adducts (Fig. 7B). Interestingly, ketoconazole (CYP3A inhibitor) failed to slow down the generation of M1-M3 in the incubation system. The observed minor inhibition of CYP3A by ketoconazole might have resulted from the dominant role of CYP1A2 in the formation of the reactive intermediates in the incubation reactions, as CYP1A2 was not inactivated. This suggests that the ability to catalyze the formation of reactive metabolites is not necessarily proportional to the degree of the resulting enzyme inactivation. For example, those P450 enzymes lacking nucleophilic amino acid residues at their active sites may not be selectively modified, so that no such enzyme inactivation could take place. Another scenario is that the resulting reactive intermediate easily diffuses from the active center of the host enzymes. It is probable that the carbene intermediate may escape from the active sites of the enzymes, such as CYPs 1A2 and $3 \mathrm{~A} 4$, which appeared to be the major enzymes responsible for the bioactivation of NC. The escaped carbene intermediate was apparently quenched by $\mathrm{H}_{2} \mathrm{O}$ to catechol, which was further metabolized to the NAC adducts we detected. The detected M1-M3 do not necessarily cause immediate toxicities.

CYP2D6 is one of the most widely investigated P450s in relation to genetic polymorphism (Teh and Bertilsson, 2012). Although CYP2D6 constitutes a relatively minor fraction of the total hepatic P450 content, the enzyme participates in the metabolism of at least $25 \%$ of marketed drugs (Bertelsen et al., 2003; Teh and Bertilsson, 2012). Further, many CYP2D6 substrates are members of pharmaceutical classes with narrow therapeutic indices, such as antiarrhythmics, antihypertensives, and antidepressants (Livezey et al., 2012). Unlike other better conserved P450 isoforms (e.g., such as CYP3A4), many CYP2D6 alleles encode enzymes that have reduced or no function compared with the wild-type enzyme (Haufroid and Hantson, 2015). Therefore, depending on the combination of CYP2D6 alleles in a given individual,

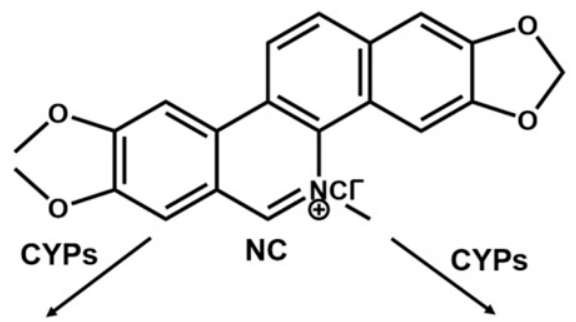<smiles>COc1cc2c3ccc4cc5c(cc4c3n(C)c2cc1OC)OCO5</smiles>

Carbene intermediate<smiles></smiles><smiles>C[N+]1(C)Cc2cc3c(cc2-c2ccc4cc(O)c(O)cc4c21)OCO3</smiles>

Catechol

[O]<smiles></smiles>

Quinone intermediate
Scheme 1. Proposed pathways for the formation of reactive intermediate(s) and NAC adducts by P450-mediated metabolism of NC. 
drug-metabolizing activities associated with the enzyme can vary extensively. For example, approximately $5 \%-10 \%$ of the Caucasian population are deficient in this enzyme, resulting in a poor metabolizer phenotype and the potential for adverse interactions with drugs possessing a narrow therapeutic window (Hutzler et al., 2004). In addition, the inactivation of CYP2D6 may lead to serious clinical side effects, as exemplified by debrisoquine metabolism by individuals with a CYP2D6 poor-metabolizer phenotype (Livezey et al., 2012). Among the strongest CYP2D6 inhibitors, that is, those causing a $>5$-fold increase in the plasma area under the curve or AUC values or more than $80 \%$ decrease in clearance, are bupropion, fluoxetine, paroxetine, cinacalcet, and quinidine. Other less potent CYP2D6 inhibitors are duloxetine, sertraline, terbinafine, amiodarone, cimetidine, and ritonavir (Haufroid and Hantson, 2015). The above experimental results manifest that NC presents a risk of drug-drug interactions during coadministration of other CYP2D6 substrates with narrow therapeutic indices, especially in the poorly metabolizing population.

In summary, $\mathrm{NC}$ is characterized as a mechanism-based inactivator of CYP2D6, with the electrophilic intermediate carbene possibly giving rise to enzyme inactivation. Three NAC adducts were identified in microsomal incubations with $\mathrm{NC}$ trapped by NAC. However, CYP1A2 is the major enzyme responsible for the bioactivation of NC.

\section{Authorship Contributions}

Participated in research design: Zheng, Peng.

Conducted experiments: Mao, Hu, Wang, Zhang, Zhou.

Performed data analysis: Mao.

Wrote or contributed to the writing of the manuscript: Mao, Zheng.

\section{References}

Arthur HR, Hui WH, and Ng YL (1959) An examination of the rutaceae of Hong Kong. Part II. The alkaloids, nitidine and oxynitidine, from Zanthoxylum nitidum. J Chem Soc 0:1840-1845. Bertelsen KM, Venkatakrishnan K, Von Moltke LL, Obach RS, and Greenblatt DJ (2003) Apparent mechanism-based inhibition of human CYP2D6 in vitro by paroxetine: comparison with fluoxetine and quinidine. Drug Metab Dispos 31:289-293.

Bouquet J, Rivaud M, Chevalley S, Deharo E, Jullian V, and Valentin A (2012) Biological activities of nitidine, a potential anti-malarial lead compound. Malar J 11:67.

Chen J, Wang J, Lin L, He L, Wu Y, Zhang L, Yi Z, Chen Y, Pang X, and Liu M (2012) Inhibition of STAT3 signaling pathway by nitidine chloride suppressed the angiogenesis and growth of human gastric cancer. Mol Cancer Ther 11:277-287.

Danton AC, Montastruc F, Sommet A, Durrieu G, Bagheri H, Bondon-Guitton E, Lapeyre-Mestre M, and Montastruc JL (2013) Importance of cytochrome P450 (CYP450) in adverse drug reactions due to drug-drug interactions: a PharmacoVigilance study in France. Eur J Clin Pharmacol 69:885-888.

Erve JC, Gauby S, Maynard JW, Jr, Svensson MA, Tonn G, and Quinn KP (2013) Bioactivation of sitaxentan in liver microsomes, hepatocytes, and expressed human P450s with characterization of the glutathione conjugate by liquid chromatography tandem mass spectrometry. Chem Res Toxicol 26:926-936.

Fang Z, Tang Y, Jiao W, Xing Z, Guo Z, Wang W, Xu Z, and Liu Z (2014) Nitidine chloride induces apoptosis and inhibits tumor cell proliferation via suppressing ERK signaling pathway in renal cancer. Food Chem Toxicol 66:210-216.

Fowler S and Zhang H (2008) In vitro evaluation of reversible and irreversible cytochrome P450 inhibition: current status on methodologies and their utility for predicting drug-drug interactions. AAPS J 10:410-424.

Gakunju DM, Mberu EK, Dossaji SF, Gray AI, Waigh RD, Waterman PG, and Watkins WM (1995) Potent antimalarial activity of the alkaloid nitidine, isolated from a Kenyan herbal remedy. Antimicrob Agents Chemother 39:2606-2609.

Haefeli WE and Carls A (2014) Drug interactions with phytotherapeutics in oncology. Expert Opin Drug Metab Toxicol 10:359-377.

Haufroid V and Hantson P (2015) CYP2D6 genetic polymorphisms and their relevance for poisoning due to amfetamines, opioid analgesics and antidepressants. Clin Toxicol (Phila) 53 501-510.

Hu J, Zhang WD, Liu RH, Zhang C, Shen YH, Li HL, Liang MJ, and Xu XK (2006) Benzophenanthridine alkaloids from Zanthoxylum nitidum (Roxb.) DC, and their analgesic and anti-inflammatory activities. Chem Biodivers 3:990-995.

Hutzler JM, Melton RJ, Rumsey JM, Schnute ME, Locuson CW, and Wienkers LC (2006) Inhibition of cytochrome P450 3A4 by a pyrimidineimidazole: evidence for complex heme interactions. Chem Res Toxicol 19:1650-1659.
Hutzler JM, Melton RJ, Rumsey JM, Thompson DC, Rock DA, and Wienkers LC (2008) Assessment of the metabolism and intrinsic reactivity of a novel catechol metabolite. Chem Res Toxicol 21:1125-1133.

Hutzler JM, Steenwyk RC, Smith EB, Walker GS, and Wienkers LC (2004) Mechanism-based inactivation of cytochrome P450 2D6 by 1-[(2-ethyl-4-methyl-1H-imidazol-5-yl)methyl]4-[4-(trifluoromethyl)-2-pyridinyl]piperazine: kinetic characterization and evidence for apoprotein adduction. Chem Res Toxicol 17:174-184.

Iwasaki H, Okabe T, Takara K, Toda T, Shimatani M, and Oku H (2010a) Tumor-selective cytotoxicity of benzo[c]phenanthridine derivatives from Toddalia asiatica Lam. Cancer Chemother Pharmacol 65:719-726.

Iwasaki H, Okabe T, Takara K, Yoshida Y, Hanashiro K, and Oku H (2010b) Down-regulation of lipids transporter ABCA1 increases the cytotoxicity of nitidine. Cancer Chemother Pharmacol 66:953-959.

Jan KC, Chang YW, Hwang LS, and Ho CT (2012) Tissue distribution and cytochrome P450 inhibition of sesaminol and its tetrahydrofuranoid metabolites. J Agric Food Chem 60: $8616-8623$.

Kent UM, Juschyshyn MI, and Hollenberg PF (2001) Mechanism-based inactivators as probes of cytochrome P450 structure and function. Curr Drug Metab 2:215-243.

Li W, Yin H, Bardelang D, Xiao J, Zheng Y, and Wang R (2017) Supramolecular formulation of nitidine chloride can alleviate its hepatotoxicity and improve its anticancer activity. Food Chem Toxicol 109:923-929.

Liao J, Xu T, Zheng JX, Lin JM, Cai QY, Yu DB, and Peng J (2013) Nitidine chloride inhibits hepatocellular carcinoma cell growth in vivo through the suppression of the JAK1/STAT3 signaling pathway. Int J Mol Med 32:79-84.

Liu L, Sun S, Rui H, and Li X (2017) In vitro inhibitory effects of dihydromyricetin on human liver cytochrome P450 enzymes. Pharm Biol 55:1868-1874.

Livezey M, Nagy LD, Diffenderfer LE, Arthur EJ, Hsi DJ, Holton JM, and Furge LL (2012) Molecular analysis and modeling of inactivation of human CYP2D6 by four mechanism based inactivators. Drug Metab Lett 6:7-14.

Ma J, Chu Z, Lu JBL, Liu J, Zhang Q, Liu Z, and Tang D (2018) The cytochrome P450 enzyme responsible for the production of (Z)-Norendoxifen in vitro. Chem Biodivers 15.

Moruno-Dávila MA, Garrido-del Solo C, García-Moreno M, Havsteen BH, Garcia-Sevilla F, Garcia-Cánovas F, and Varón R (2001) Kinetic analysis of enzyme systems with suicide substrate in the presence of a reversible competitive inhibitor, tested by simulated progress curves. Int J Biochem Cell Biol 33:181-191.

Murray M (2000) Mechanisms of inhibitory and regulatory effects of methylenedioxyphenyl compounds on cytochrome P450-dependent drug oxidation. Curr Drug Metab 1:67-84.

Ou X, Lu Y, Liao L, Li D, Liu L, Liu H, and Xu H (2015) Nitidine chloride induces apoptosis in human hepatocellular carcinoma cells through a pathway involving p53, p21, Bax and Bcl-2. Oncol Rep 33:1264-1274.

Pan X, Han H, Wang L, Yang L, Li R, Li Z, Liu J, Zhao Q, Qian M, Liu M, et al. (2011) Nitidine chloride inhibits breast cancer cells migration and invasion by suppressing c-Src/FAK associated signaling pathway. Cancer Lett 313:181-191.

Rodrigues AD (1999) Integrated cytochrome P450 reaction phenotyping: attempting to bridge the gap between cDNA-expressed cytochromes $\mathrm{P} 450$ and native human liver microsomes. Biochem Pharmacol 57:465-480.

Salminen KA, Meyer A, Imming P, and Raunio H (2011) CYP2C19 progress curve analysis and mechanism-based inactivation by three methylenedioxyphenyl compounds. Drug Metab Dispos 39:2283-2289.

Song JH, Sun DX, Chen B, Ji DH, Pu J, Xu J, Tian FD, and Guo L (2011) Inhibition of CYP3A4 and CYP2C9 by podophyllotoxin: implication for clinical drug-drug interactions. J Biosci 36: 879-885.

Tan GT, Pezzuto JM, Kinghorn AD, and Hughes SH (1991) Evaluation of natural products as inhibitors of human immunodeficiency virus type 1 (HIV-1) reverse transcriptase. J Nat Prod 54: 143-154.

Taxak N, Patel B, and Bharatam PV (2013) Carbene generation by cytochromes and electronic structure of heme-iron-porphyrin-carbene complex: a quantum chemical study. Inorg Chem 52: 5097-5109.

Teh LK and Bertilsson L (2012) Pharmacogenomics of CYP2D6: molecular genetics, interethnic differences and clinical importance. Drug Metab Pharmacokinet 27:55-67.

Wang Z, Jiang W, Zhang Z, Qian M, and Du B (2012) Nitidine chloride inhibits LPS-induced inflammatory cytokines production via MAPK and NF-kappaB pathway in RAW 264.7 cells. J Ethnopharmacol 144:145-150.

Watanabe A, Nakamura K, Okudaira N, Okazaki O, and Sudo K (2007) Risk assessment for drugdrug interaction caused by metabolism-based inhibition of CYP3A using automated in vitro assay systems and its application in the early drug discovery process. Drug Metab Dispos $\mathbf{3 5}$ $1232-1238$.

Wójcikowski J, Pichard-Garcia L, Maurel P, and Daniel WA (2004) The metabolism of the piperazine-type phenothiazine neuroleptic perazine by the human cytochrome P-450 isoenzymes. Eur Neuropsychopharmacol 14:199-208.

Yang AH, He X, Chen JX, He LN, Jin CH, Wang LL, Zhang FL, and An LJ (2015) Identification and characterization of reactive metabolites in myristicin-mediated mechanism-based inhibition of CYP1A2. Chem Biol Interact 237:133-140.

Address correspondence to: Dr. Jiang Zheng, Wuya College of Innovation, Shenyang Pharmaceutical University, Shenyang, 110016, P. R. China; State Key Laboratory of Functions and Applications of Medicinal Plants, Key Laboratory of Pharmaceutics of Guizhou Province, Guizhou Medical University, Guiyang, Guizhou, 550004, P. R. China. E-mail: zhengneu@yahoo.com; or Dr. Ying Peng, Wuya College of Innovation, Shenyang Pharmaceutical University, Shenyang, Liaoning, 110016, P. R. China. E-mail: yingpeng1999@163.com 